\title{
Extreme winter precipitation in the Iberian Peninsula in 2010: anomalies, driving mechanisms and future projections
}

\author{
Sergio M. Vicente-Serrano ${ }^{1, *}$, Ricardo M. Trigo ${ }^{2}$, Juan I. López-Moreno ${ }^{1}$, \\ Margarida L. R. Liberato ${ }^{2}$, Jorge Lorenzo-Lacruz ${ }^{1}$, Santiago Beguería ${ }^{3}$, \\ Enrique Morán-Tejeda ${ }^{1}$, Ahmed El Kenawy ${ }^{1}$ \\ ${ }^{1}$ Instituto Pirenaico de Ecología, and ${ }^{3}$ Estación Experimental de Aula Dei, CSIC, Zaragoza 50059, Spain \\ ${ }^{2}$ Centro de Geofíisica da Universidade de Lisboa (CGUL), Instituto Dom Luiz (IDL), Lisbon 1749-016, Portugal
}

\begin{abstract}
This work provides a first assessment of the outstanding characteristics of the anomalous precipitation occurrence in the winter of 2010 over the Iberian Peninsula, as well as on the associated atmospheric driving mechanisms. Large areas of Iberia, those located in the western and southern sectors, registered a new historical maximum in winter precipitation values. Simultaneously, the most extreme, negative North Atlantic Oscillation (NAO) index for winter was recorded in 2010. The anomalous pressure gradient in the North Atlantic region steered a large number of low pressure systems via an unusually southern path, directly influencing Iberia and northern Africa. Storms were frequent, and a high number of days occurred with weather types prone to cause precipitation. In addition, the most extreme daily precipitation episodes were recorded during the period with the strongest negative NAO index. Global climate models for the entire 21st century show that strong negative NAO winters, similar to that which occurred in 2010, may be expected in the future.
\end{abstract}

KEY WORDS: North Atlantic Oscillation · Extreme events $\cdot$ Natural hazards $\cdot$ Atmospheric circulation $\cdot$ Climate change

Resale or republication not permitted without written consent of the publisher

\section{INTRODUCTION}

Precipitation in the Mediterranean region is characterised by strong interannual variability and the occurrence of very dry or moist seasons. The winter (defined here as December-January-February-March, DJFM) of 2010 was particularly anomalous, and in large areas of the Iberian Peninsula the most extreme precipitation values recorded since the beginning of regular measurements at the end of the 19th or beginning of the 20th century were noted. This unusually wet winter over Iberia reflects a regional feature resulting from wider anomalous conditions in the atmospheric circulation at a global scale (Cattiaux et al. 2010, Wang et al. 2010). In Europe, several intense cold spells and an unusual persistence of snow cover were observed, although it was not the coldest winter (Cattiaux et al.
2010). Equally, large areas of the eastern United States also recorded their snowiest winter ever (Seager et al. 2010) and several cities even registered recordbreaking daily low temperatures (Wang et al. 2010).

Higher than average winter precipitation over the Iberian Peninsula usually produces positive impacts on the region, since the water stored in the soil during the winter largely determines the crop production in rain-fed areas (Austin et al. 1998, Vicente-Serrano et al. 2006). Additionally it guarantees the availability of water for irrigated agriculture and urban consumption the following summer given the large capacity for reservoir storage in the region (López-Moreno et al. 2009, Lorenzo-Lacruz et al. 2010). Nevertheless, very wet winters tend to comprise several extreme precipitation events, and these episodes can also cause havoc, namely through more frequent river floods, urban 
inundations and other natural hazards, such as landslides (e.g. Zezere et al. 2008). During the winter 2010, large areas of the Iberian Peninsula, particularly those located in the south and southwest, were affected by floods, resulting in severe socio-economic effects in many agricultural areas, affecting road traffic, buildings and infrastructures, and causing the collapse of houses, as well as 9 deaths in southern Spain (an area particularly affected by extreme precipitation events). Besides these unfortunate casualties, southern Iberia also registered overflows of several rivers and road and railway blockages, as well as the need to evacuate humans from several areas and provide housing for ca. 1000 persons affected by flooding (www.mma.es/ secciones/acm/aguas_continent_zonas_asoc/ons/mapa_ informe_ons/pdf/inf_ejecutivo_inundaciones100317_1. pdf). Moreover, several localities in the basin of Guadalquivir were affected by closed roads and lack of transportation. Insurance companies have had to pay $130 \mathrm{M} €$ to farmers as a consequence of crop damages, but agricultural associations have estimated that in southern Spain alone the crop damages actually amount to $807 \mathrm{M€}$, and the damages in infrastructure (greenhouses, tracks, etc.) amount to another $72 \mathrm{M}$. Reservoir water storage in the Guadalquivir basin is an example of positive effects of the wet winter. The average water stored in the previous 10 yr (2000-2009) was $4.6 \times 10^{9} \mathrm{~m}^{3}$, whereas, at the end of the winter 2010 , it was $7.25 \times 10^{9} \mathrm{~m}^{3}$. Similar numbers are found for other relevant southern Iberian basins, such as the Guadiana $\left(5.95\right.$ vs. $\left.8.0 \times 10^{9} \mathrm{~m}^{3}\right)$ or the Segura (0.28 vs. $0.79 \times$ $10^{9} \mathrm{~m}^{3}$ ). This large increment in water stored in large dams explains the very high hydropower production in Spain during the winter 2010 (17.1 million MW h), whereas the average over the last 10 winters was 11.5 million MW h.

The most important mechanism responsible for the strong interannual precipitation variability observed in the western Mediterranean region is the North Atlantic Oscillation (NAO) (e.g. Rodríguez-Puebla et al. 1998, Trigo et al. 2002), particularly during the winter months, in which this pattern is more active (Hurrell et al. 2003). It is widely known that the negative phases of the NAO induce above-normal precipitation in southern Europe, particularly over the west and southwest sectors of the Iberian Peninsula (Hurrell \& Van Loon 1997, Trigo et al. 2002), areas which are subject to the influence of Atlantic low pressure systems.

The NAO shows large interannual variabilities (Hurrell 1995), and in the winter of 2010 the most extreme, negative NAO index was recorded since the availability of data (i.e. since 1823 for the NAO index, based on the Gibraltar-Iceland definition; Jones et al. 1997). It has been shown that the extremely cold winter in many areas of the Northern Hemisphere (including the USA, Europe and China) (Seager et al. 2010, see www.knmi.nl/cms/content/79165) was associated with record-breaking negative values of the Arctic Oscillation (AO) index, particularly for December 2009 (Wang et al. 2010). This is relevant because some authors regard the NAO mode merely as the regional pattern of the more symmetric AO mode (Baldwin \& Dunkerton 1999, Wallace 2000). The physical mechanisms that caused the extreme AO/NAO indices in 2010 have not yet been analysed in depth. However, recent studies have shown that the strong phase of the El NiñoSouthern Oscillation (ENSO) may have played a relevant role in causing the surface climate anomalies in the Northern Hemisphere, since the El Niño episode was the strongest since the 1997-1998 winter season and the fifth strongest since 1950 (www.ncdc.noaa. gov/special-reports/2009-2010-cold-season.html). Propagation of the ENSO influences across the Northern Hemisphere and the North Atlantic region is now relatively well established (e.g. Trenberth \& Guillemot 1996, Brönnimann 2007). Brönnimann et al. (2004) demonstrated, by means of dynamic models, that the very extreme winters between 1940 and 1942 in Europe were determined by a propagation of ENSO effects from the troposphere to stratosphere, affecting the AO phase. This could explain why the AO was very negative from June 2009 onwards and the winter was characterised by a southern displacement in the position of the mid-latitude jet stream (L'Heureux et al. 2010).

In the present study, we analyse the influence of this extreme episode of atmospheric circulation on the spatial and temporal anomalies of precipitation over the Iberian Peninsula, showing the driving atmospheric mechanisms that explain the anomalous precipitation conditions and determining, within the current stateof-the-art, how such anomalous conditions may be repeated in the future according to global climate model (GCM) projections.

\section{DATA AND METHODS}

\subsection{Data sets}

The study drew data from 6 different data sets. (1) The monthly precipitation records of 45 precipitation observatories from January 1910 to March 2010 were used. The series were carefully homogenized and quality controlled (Vicente-Serrano 2005). They were distributed homogenously across the Iberian Peninsula (see Fig. 2), covering all precipitation regimes found in the region. The daily precipitation series for 38 of the same stations for the period 1965-2010 were also available. 
(2) A station-based monthly NAO index was used. The series was obtained from the Climate Research Unit of the University of East Anglia (www.cru.uea. ac.uk/cru/data/nao/) and was calculated from the difference between the normalized pressures in Reykjavik (Iceland) and Gibraltar (southern Iberian Peninsula) (Jones et al. 1997). The series covered the period spanning between 1823 and March 2010.

(3) Monthly values of gridded Northern Hemisphere sea-level pressure (SLP) were extracted from the National Center for Atmospheric Research (http://dss. ucar.edu/datasets/ds010.1/) (Trenberth \& Paolino 1980) for the period 1899-2010, in order to derive the spatial pattern of SLP anomalies in the winter 2010. From this dataset, we also used a daily SLP series for the grid point nearest to Reykiavik $\left(65^{\circ} \mathrm{N} ; 20^{\circ} \mathrm{W}\right)$ and Gibraltar $\left(35^{\circ} \mathrm{N} ; 5^{\circ} \mathrm{W}\right)$ (http://dss.ucar.edu/datasets/ ds010.0/) to obtain a daily NAO index for the winter 2010, following the same approach used by Jones et al. (1997). Moreover, the series of daily SLPs for 16 points on the Iberian Peninsula and in the neighbouring areas (see López-Moreno \& Vicente-Serrano 2007) were also based on the same dataset used to classify daily weather types during the period 1899-2010, following the approach of Jenkinson \& Collison (1977).

(4) The monthly averages of U and V components (m $\mathrm{s}-1)$ for winds at the surface $(10 \mathrm{~m})$ and at $250 \mathrm{hPa}$ levels were obtained from the NCEP/NCAR reanalysis dataset (www.esrl.noaa.gov/psd/data/gridded/data. ncep.reanalysis.derived.html) (Kalnay et al. 1996) for the period between 1948 and 2010. The purpose was to determine the direction and intensity of winter flows at the surface and at the characteristic level of the jet stream during the winter 2010, to be compared with the observations of other extreme, negative NAO years and the climatology records.

(5) The detection and tracking of North Atlantic cyclones is based on an algorithm first developed for the Mediterranean region by Trigo et al. (1999) and later adapted to the entire North Atlantic area (Trigo 2006). Both the detection and tracking schemes were performed using $6 \mathrm{~h} \mathrm{SLP}$, available from NCEP/NCAR reanalysis on a $2.5^{\circ} \times 2.5^{\circ}$ grid from 1958 to 2010 .

(6) Simulations of SLP under the CMIP3 project http://www-pcmdi.llnl.gov/ipcc/about_ipcc.php were downloaded from the KNMI Climate Explorer website (http://climexp.knmi.nl/) to simulate the NAO index from 1875 to 2100. Selection of the models was based on the availability of simulations under the A1B1 scenario in the KNMI dataset. The models selected were: CCMA-CGCM3.1_T63 (CCMA), MRI-CGCM2.3.2 (MRI), UKMO-HADCM3 (UKMO), ECHAM5/MPI OM (MPI), ECHO-G/MIUB (MIUB), MIROC 3.2 (MIROC), GFDL/CM2.0 (GFDL), CSIRO Mk3.5 (CSIRO), CNRM/ CM3 (CNRM) and BCCR/BCM2.0 (BCM). The NAO index was derived using the outputs for the coordinates $65^{\circ} \mathrm{N} 20^{\circ} \mathrm{W}$ and $35^{\circ} \mathrm{N} 5^{\circ} \mathrm{W}$ and the reference period 1950-1980, so that it was comparable with the Jones et al. (1997) NAO index. SLPs from 1875 to 2000 were simulated according to the 'climate of the 20th century experiment (20C3M)'; from 2010 onwards, simulations assumed a moderate increase in green house gases according to the A1B scenario.

\subsection{Analysis}

The winter (DJFM) 4 mo standardized precipitation index (SPI) (McKee et al. 1993) was obtained from the 45 monthly precipitation series used. The index was calculated following a Pearson III distribution by means of the algorithm formulated by Vicente-Serrano (2006). This index allows determination of the magnitude of the precipitation anomaly for each winter and permits a spatial comparison independent of the distinct precipitation regime that characterises each region. The correlation between the winter 4 mo SPI from 1910 to 2010 and the winter NAO index was computed for each of the 45 observatories.

To analyse the atmospheric mechanisms that drove the influence of the 2010 NAO on the Iberian winter precipitation (both in terms of the magnitude of the anomalies and the spatial patterns), we employed 3 complementary methods: (1) SLP and upper level anomalies, (2) objective storm-tracking and (3) weather typing. The first approach gave us the winter SLP anomalies for the North Atlantic region and allowed us to plot the magnitude and direction of the surface and $250 \mathrm{hPa}$ wind flows. The 2 remaining methodologies required additional technical details.

Cyclones are objectively identified as minima in SLP fields, fulfilling a set of conditions regarding the central pressure $(<1020 \mathrm{hPa})$, and the pressure gradient - averaged over an area of about $1100 \mathrm{~km}^{2}$ — has to be at least $0.55 \mathrm{hPa} 100 \mathrm{~km}^{-1}$. The tracking is based on a nearest neighbour search in consecutive charts, assuming that the speed of individual storms is $<50 \mathrm{~km} \mathrm{~h}^{-1}$ in the westward direction and $110 \mathrm{~km} \mathrm{~h}^{-1}$ in any other. Further details on the cyclone detecting and tracking method may be found in Trigo et al. (1999) and Trigo (2006).

Daily weather types over the Iberian Peninsula were obtained from winter 1900 to 2010 using the objective weather typing system of Jenkinson \& Collison (1977) based on the Lamb types. The method results in discrimination of the weather type for each day among 26 possible types: anticyclonic (A), cyclonic (C), 8 directional weather types (N, NE, E, SE, $\mathrm{S}, \mathrm{SW}, \mathrm{W}$ and NW) and hybrid types between cyclonic or anticyclonic and directional. We summarized the daily weather type series in monthly series by means 
of the monthly sum of days of each weather type. The 26 weather types were reduced in 10 types to facilitate interpretation of the results by means of addition of the hybrid types to the other types, following Trigo \& DaCamara (2000).

\section{RESULTS}

\subsection{Precipitation}

Totals of precipitation recorded during the winter 2010 in large areas of Iberia have been the most extreme recorded since climate observations have been available. Table 1 shows the percentage of available stations (45) in which the monthly precipitation was higher than the 70th and 90th percentiles. Between December and February $>70 \%$ of the stations recorded values higher than the 70th percentile of the corresponding distribution. Furthermore, a high percentage of stations also showed precipitation values higher than the 90th percentile (49\% in December, $20 \%$ in January

Table 1. Percentage of stations with monthly precipitation higher than the 70th and 90th percentiles in 2010 and 1996

\begin{tabular}{|lcc|}
\hline & $>$ 70th percentile & $>$ 90th percentile \\
\hline $\mathbf{1 9 9 6}$ & & \\
Dec & 88.9 & 53.3 \\
Jan & 88.9 & 68.9 \\
Feb & 31.1 & 6.7 \\
Mar & 8.9 & 2.2 \\
$\mathbf{2 0 1 0}$ & & \\
Dec & 77.8 & 48.9 \\
Jan & 73.3 & 20.0 \\
Feb & 71.1 & 37.8 \\
Mar & 44.4 & 8.9 \\
\hline
\end{tabular}

and $38 \%$ in February). For comparison purposes, we have also included the statistics relative to the second most extreme, negative winter NAO (in 1996) to illustrate how these numbers may also be found in other extreme, negative NAO winters, albeit with a different monthly impact. Thus, in December and January of 1996 the percentage of stations with monthly precipitation above the 70th and 90th percentiles was higher than that observed in 2010, although the percentages were much lower in February and March.

As illustrative examples, between 1 December 2009 and 31 March 2010 the precipitation recorded in Lisbon (Portugal) was $958.6 \mathrm{~mm}$, i.e. the maximum observed from 1865 to 2010 (Fig. 1). In Seville (Spain), the average winter precipitation was $712.4 \mathrm{~mm}$, the maximum since 1910. In Almería, one of the driest areas of Europe with an annual average (1910-2010) of just $209.6 \mathrm{~mm}$, the 4 winter months (DJFM) 2010 registered $350.2 \mathrm{~mm}$, the maximum winter precipitation ever recorded. In Madrid, the winter precipitation was $318.1 \mathrm{~mm}$, the second highest value recorded since 1910. Nevertheless, besides the outstanding winter values described above, it is often interesting to analyse what happened at the monthly scale. Thus, Fig. 1 shows, as an example, the monthly precipitation recorded between August 2009 and May 2010 at the observatories in Lisbon (Portugal) and Seville (Spain), compared with long-term climatology (1910-2010). For Lisbon, all of the winter months (DJFM) exceeded the long-term 70th percentile, and, with the exception of January 2010, they even exceeded the 98th percentile of the monthly precipitation distribution. The corresponding analysis obtained for Seville is not as impressive; still the 4 winter months exceeded the long-term median, and 3 mo (December-February) present precipitation values above the 70th percentile, while December equals the $98 \%$ perecentile.

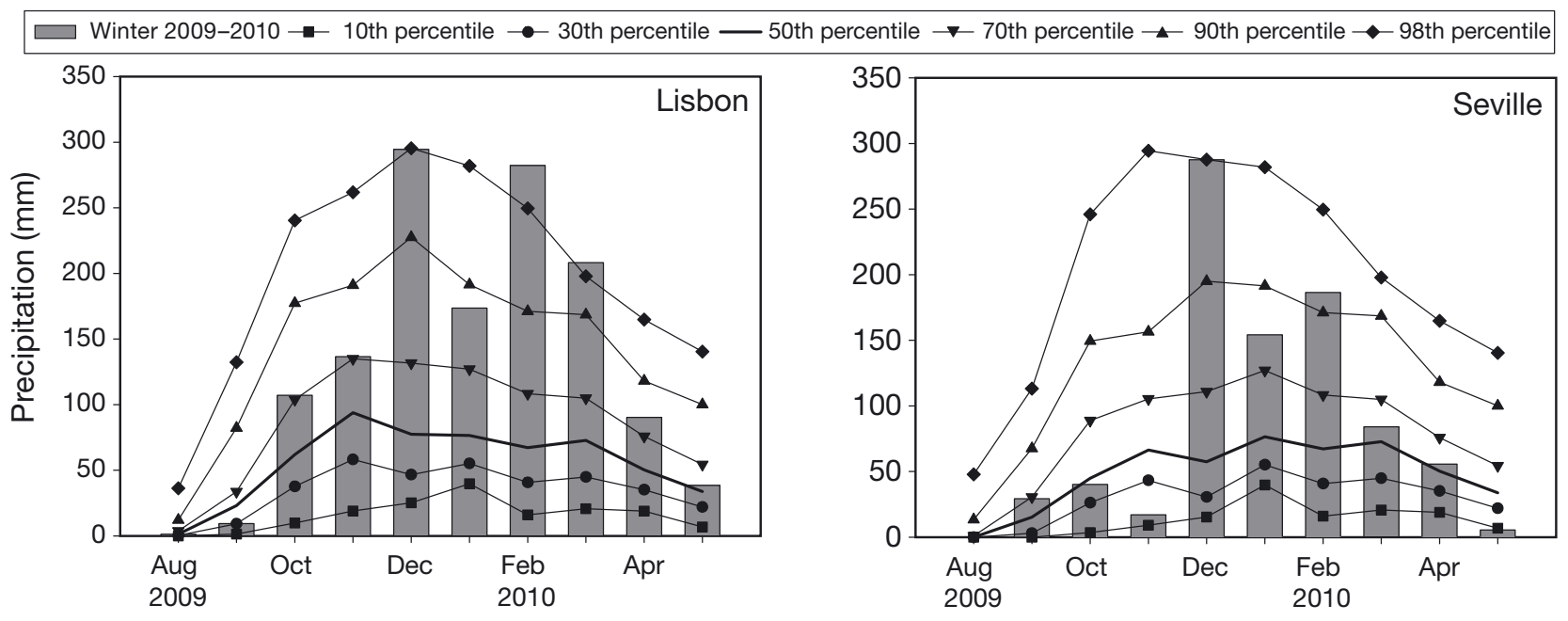

Fig. 1. Monthly precipitation values from August 2009 to May 2010 in Lisbon and Seville and long-term 10th-98th percentiles 

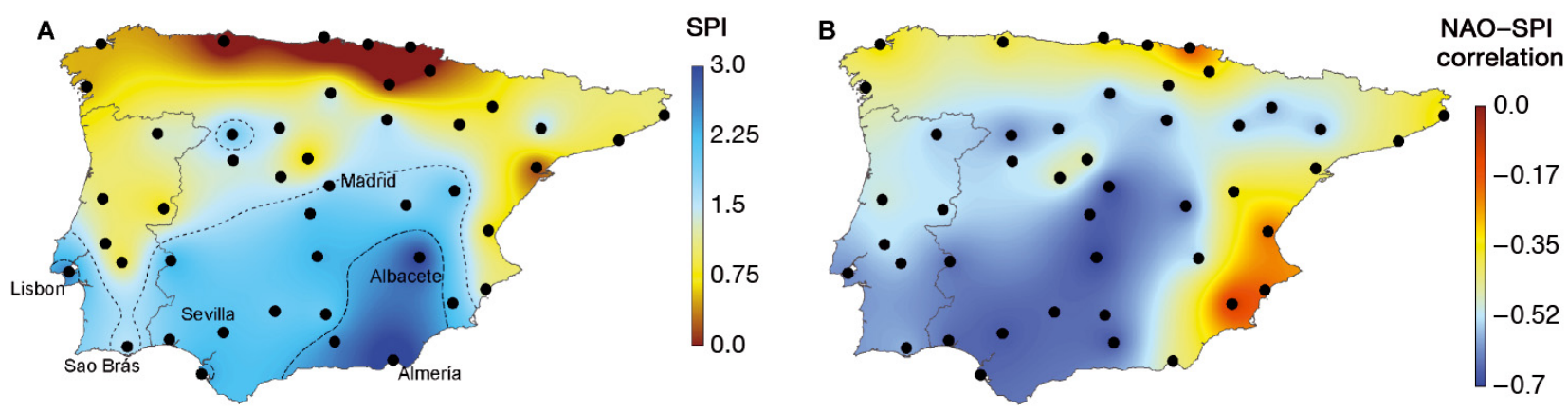

Fig. 2. (A) Spatial distribution of the 4 mo standardized precipitation index (SPI) anomalies in the winter of 2010 in relation to the 1910-2010 reference period. Dashed and solid lines: SPI $=-1.65$ and SPI $=-2.33$, respectively. (B) Spatial distribution of the winter North Atlantic Oscillation (NAO)-SPI correlations (1910-2010). Black dots: stations with monthly precipitation data 1910-2010

Fig. 2A shows the spatial distribution of the precipitation anomalies corresponding to the 4 mo SPI values in March 2010, after removing the 1910-2010 climatology. Large positive anomalies were found on most of the Iberian Peninsula, with exceptions of the northern and Mediterranean coastlands that show near-normal or even negative anomalies. In large areas of the south, west and southwest the recorded precipitation corresponds to anomalies $>2.3$, which is equivalent to a return period of 1 event every 100 yr. Moreover, in some locations, the obtained SPI value is $>3$ (depicted in deep blue colour), corresponding to a return period of 1 in 1000 yr (e.g. Almería, SPI = 3.3; Albacete, SPI = 3.05). Fig. $2 \mathrm{~B}$ shows the spatial distribution of the 1910-2010 correlation between the winter NAO and

A

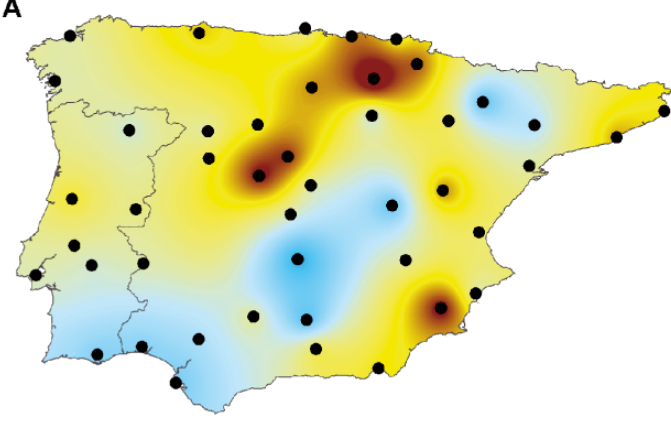

C

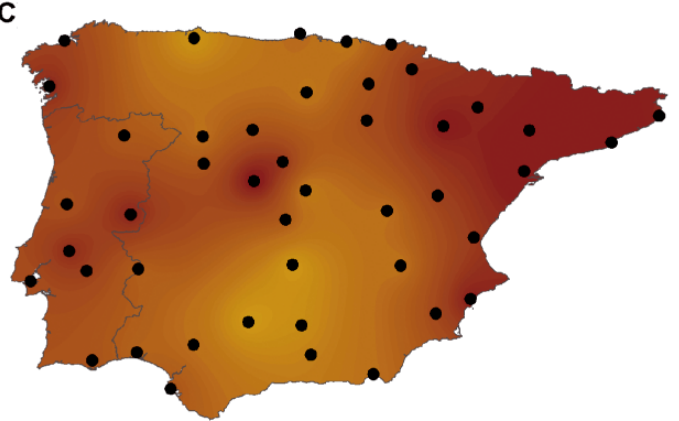

the 4 mo SPI in March. The pattern shows a clear spatial gradient (SW-NE), with the highest correlations being observed on the southwest, west and central Iberian Peninsula, whereas non-significant correlations were found in the northern coastlands and Mediterranean areas. The pattern of winter 2010 precipitation anomalies shows a high resemblance with the general pattern of winter NAO influence over the Iberian Peninsula (Trigo et al. 2002). Thus, the correlation between both spatial configurations is strong and statistically significant $(\mathrm{R}=-0.56, \mathrm{p}<0.01)$. It must be emphasised that it is rather difficult to find a pattern of SPI anomalies as similar to the spatial influence of the NAO obtained in 2010. Fig. 3 shows the SPI values for the 2 winters with the most negative NAO values prior

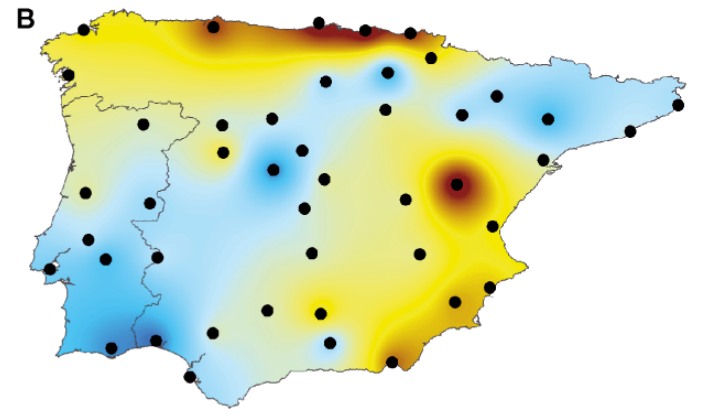

1.5
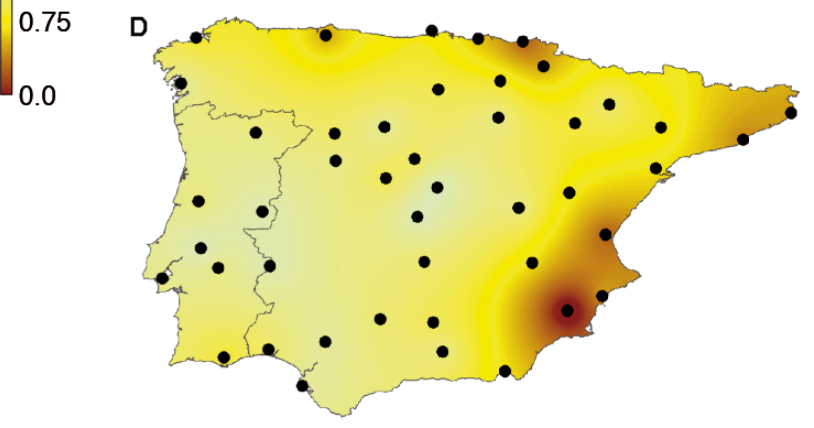

Fig. 3. (A) Standardized precipitation index (SPI) for the winter 1969, (B) SPI for the winter 1996, (C) average SPI for negative NAO winters (values between 0 and -1 ) and (D) average SPI for negative NAO winters (values between -1 and -2 ). Black dots as in Fig. 2 
to 2010, i.e 1969 and 1996. While both years reveal large areas of the Iberian Peninsula dominated with positive SPI values, neither reach the magnitude and wider spatial coverage observed in 2010. Thus, the patterns show some resemblance with 2010, with the most positive values in the south or southwest, but several differences can also be detected. We have also included an analysis of the average SPI values for the winters that recorded NAO values between 0 and -1 and the years that recorded low negative values (between -2 and -1). These years show low SPI anomalies in comparison to the winter 2010, although the spatial pattern is quite similar. In summary, these results affirm that the winter 2010 was exceptional in relation to the rest of the negative NAO winters, both in the magnitude of SPI anomalies and also in the resemblance to the pattern of NAO influence.

A daily analysis of the NAO value confirms the important role of the strong negative NAO winter to explain the extreme precipitation events recorded over large areas of the Iberian Peninsula. Fig. 4 shows the daily NAO index for the winter 2010 and the daily precipitation recorded at 2 locations of southwest Iberia, Seville (Spain) and Sao Brás (Portugal). The daily NAO index shows dominant negative values during the entire winter season. Thus, only $17 \mathrm{~d}$ (out of 120) showed mild positive values of the index during the winter. A spell of a very strong negative NAO index was recorded from 10 December 2009 to 14 January 2010. This period matches up with the strongest daily rainfall recorded at both observatories. The second negative period extends from 24 January to 31 March, with the most intense negative NAO values being recorded between 13 and 18 February, a period that is coincident with a new precipitation peak at both observatories. Moreover, during the 2 short periods characterised with positive NAO values, virtually no precipitation was recorded. The extreme winter 2010 showed a clear anomaly in the frequency of rainy days across the Iberian Peninsula. Fig. 5A shows the absolute frequency of rainy days during the winter 2010. In large areas of the west and the southwest a high number of rainy days ( $>50)$ was recorded, with a clear west-east gradient, recording lower frequencies in the Mediterranean coastlands $(<30 \mathrm{~d})$. Both the absolute magnitude and the spatial pattern differ noticeably with average winter rainy days between 1965 and 2010, characterised by a northwest-southeast gradient and a lower frequency of rainy days (Fig. 5B). Nevertheless, if the data for the winter 2010 are presented as a percentage of rainy days compared to the average, they show a clear north-south gradient, with maximum values recorded in the south and southeast of Spain and with the number of rainy days about $180-240 \%$ of the historical average (Fig. 5C). Thus, this pattern resembles, with some differences, the pattern of SPI anomalies recorded in the winter 2010, which indicates that the high precipitation recorded in these areas during the winter 2010 was clearly related to the increase in the frequency of rainy days. Nevertheless, this pattern cannot be generalised to other areas. For example, the Atlantic coastlands and some central areas of the Iberian Peninsula do not show a large anomaly in the frequency of rainy days, but the SPI anomaly was very high $(>1.65)$. These areas showed a number of days with precipitation above the historical 95th percentile (Fig. 5D). As a representative example, in Lisbon, precipitation above the 95th per-
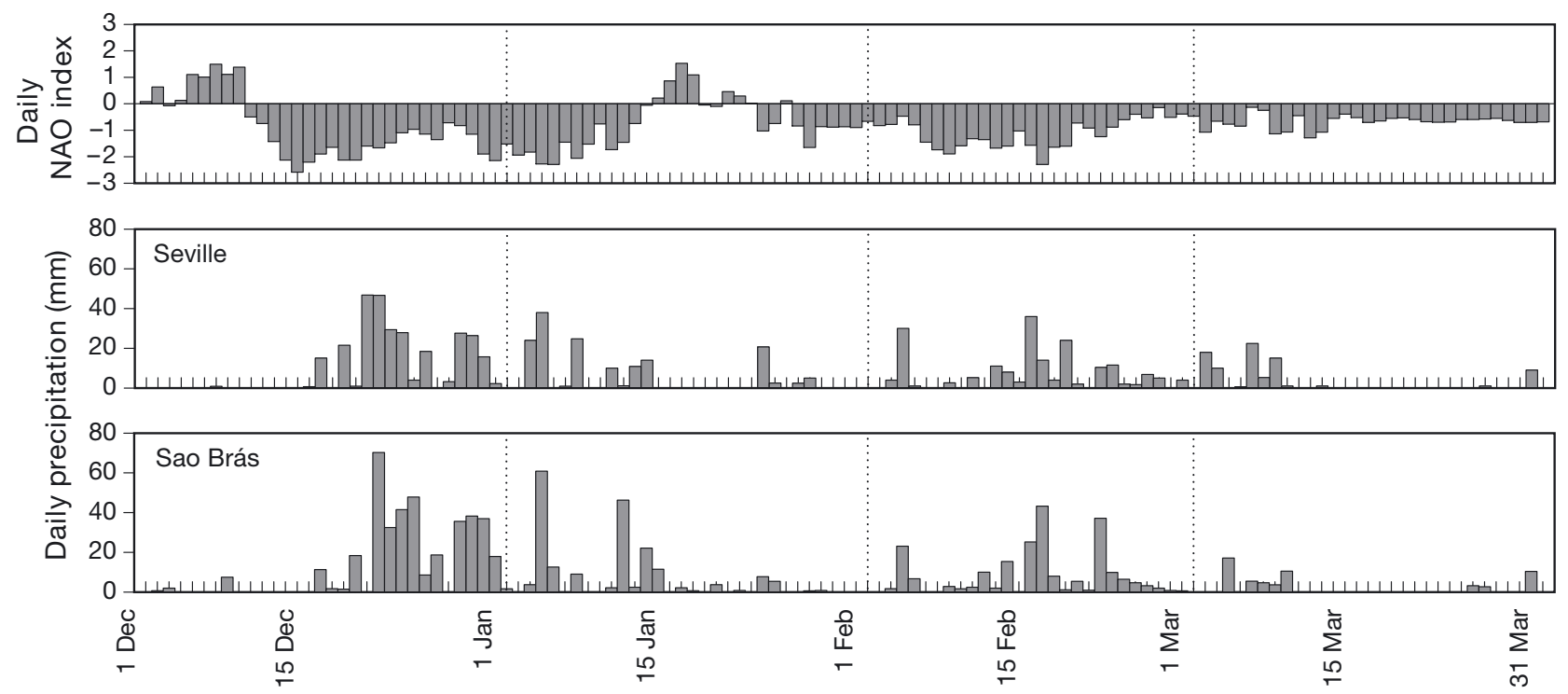

Records in (middle panel) Seville and (lower panel) Sao Brás

Fig. 4. Daily NAO index for winter 2010 (top) and daily precipitation records for Seville (middle) and Sao Brás (bottom) 

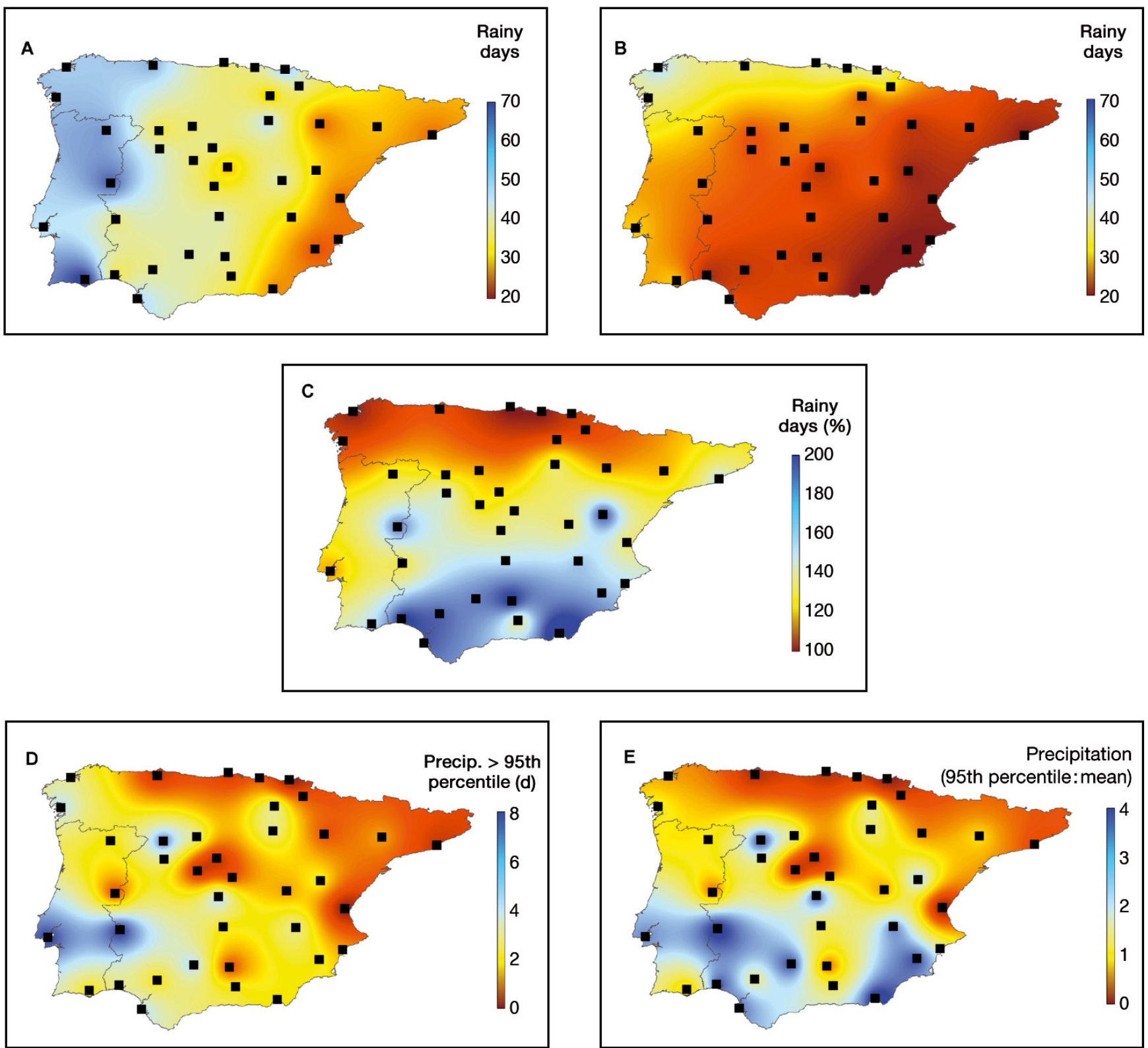

Fig. 5. (A) Spatial distribution of the number of rainy days during the winter 2010. (B) Average rainy days during the winter (1965-2010). (C) Percentage of rainy days in the winter 2010 compared to the average. (D) Number of days recording precipitation >95th percentile during the winter 2010. (E) Ratio of number of days with precipitation >95th percentile compared to the average. Black squares: stations with daily precipitation data 1965-2010

centile was recorded on $8 \mathrm{~d}$ during the winter 2010. Thus, the number of precipitation days above this threshold also shows a north-south gradient, with maximum values recorded in the southeast and southwest (Fig. 5E).

\subsection{Large-scale atmospheric circulation patterns}

We have made an effort to synthesize the most relevant large-scale features that characterise the anom- alous atmospheric circulation over the North Atlantic and Europe (Figs. 6-9). The spatial distributions of the SLP anomalies for the North Atlantic region during the winter 2010 is shown in Fig. 6A, as well as for the other 2 extreme seasonal NAO years: 1969 (Fig. 6B) and 1996 (Fig. 6C). Additionally, we have represented the average anomalous SLP field for weak $(-1<\mathrm{NAO}<0$; Fig. 6D) and moderately negative winters $(-2<\mathrm{NAO}<-1$; Fig. 6E). In 2010, the SLP anomalies show a clear north-south-oriented dipole, with strong positive (negative) anomalies located over the Iceland/Greenland 

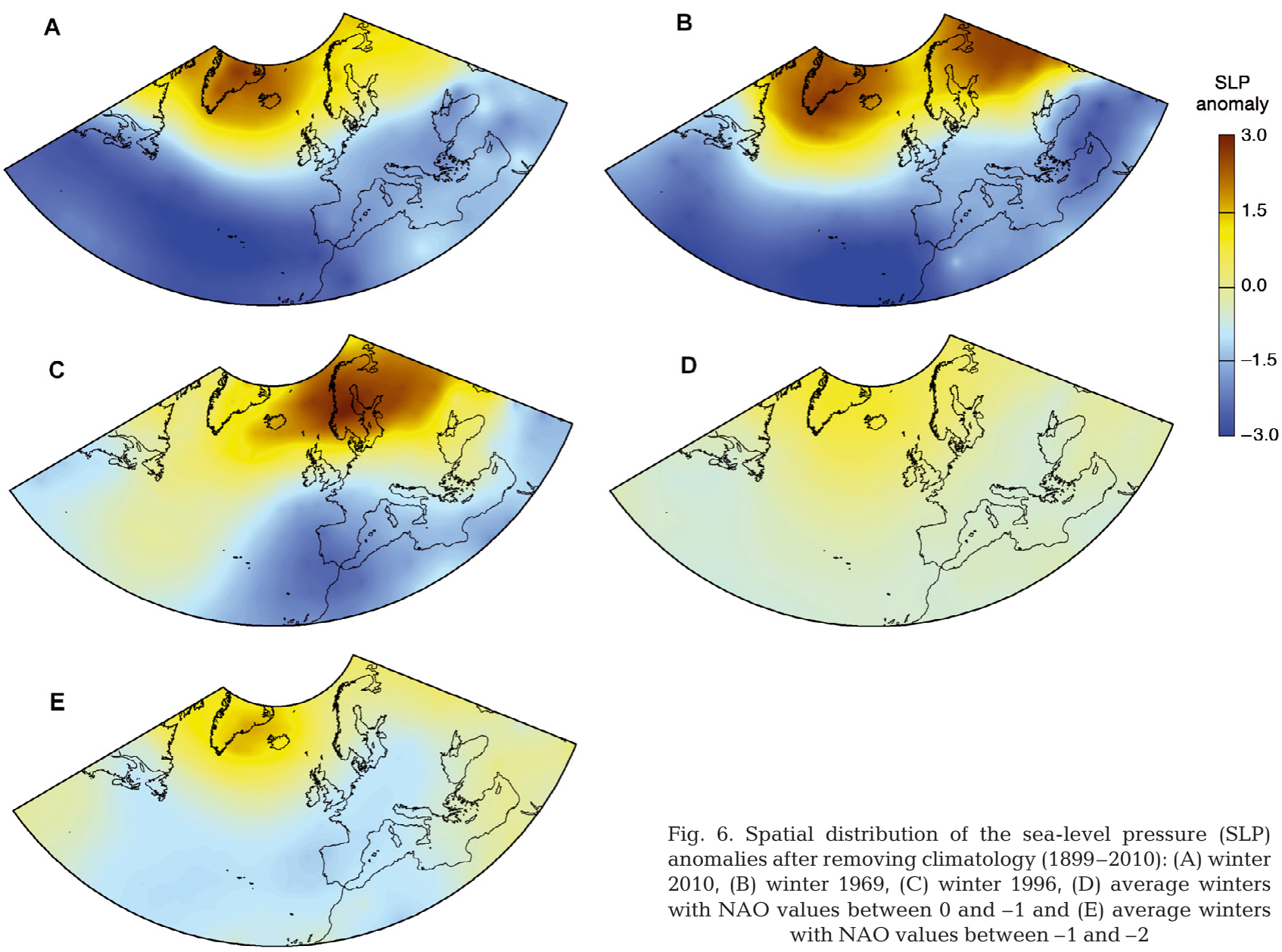

Fig. 6. Spatial distribution of the sea-level pressure (SLP) anomalies after removing climatology (1899-2010): (A) winter 2010, (B) winter 1969, (C) winter 1996, (D) average winters with NAO values between 0 and -1 and (E) average winters with NAO values between -1 and -2

(Azores) region. This pattern clearly corresponds to a strong negative winter NAO, with the southern dipole extending throughout most of the Mediterranean region. Anomalies have caused dominant upward (vertical) flows affecting all of southern Europe. A similar pattern was found in the winter of 1969, although the northern dipole was more extended, with positive anomalies also covering northern Europe. In contrast, in 1996, the NAO pattern was clearly displaced to the east, with the northern dipole centred over Scandinavia, and the southern dipole, over the Iberian Peninsula. In any case, the patterns obtained for all of these 3 extreme NAO winters clearly differ in magnitude from the patterns observed for the other negative (but non-extreme) NAO years. In fact, although the spatial pattern of the average anomalies tends to reproduce the configuration obtained for the most negative NAO winters, the magnitude of the SLP anomalies is much lower. This behaviour indicates that the well-defined NAO configurations are only observed for the most extreme, negative winters and, additionally, that some variability may be recorded among extreme events, as revealed by the 1996 event, which shows a displaced pattern to the east.
The negative pressure anomalies in the southern part of the North Atlantic region and the large pressure gradients in 2010 have caused the dominant influence of strong southwesterly wind surface flows in the southern and western areas of the Iberian Peninsula, with wind vectors of high intensity affecting the southwestern areas (Fig. 7A). The dominant surface circulation was very anomalous in relation to average conditions (Fig. 7F), since the common winter surface flows affecting the Iberian Peninsula are in a west- and northwest-dominant pattern. Thus, south and west of the Iberian Peninsula, the dominant flows are to the north and northeast, given the usual position of the Azores anticyclone, but also the relief configuration. Dominant surface southwest flows seem to be the common pattern for the most extreme, negative NAO winters like 1969 and 1996 (Fig. 7B and C, respectively), although the high intensity of the southwest surface flows recorded in 2010 was unknown for all other negative NAO years. In contrast, the weak and moderate negative NAO years (Fig. 7D and E) do not-on average-show dominant southwest surface flows, nor a high intensity of wind flows. 



Fig. 7. Average direction and magnitude of $10 \mathrm{~m}$ flows (A) in the winter 2010, (B) in the winter 1969, (C) in the winter 1996, (D) in the winters with NAO values between 0 and -1 (1948-2010), (E) in the winters with NAO values between -1 and -2 (1948-2010) and $(\mathrm{F})$ climatology of the average direction and magnitude of $10 \mathrm{~m}$ flows (1948-2010)

Fig. 8 shows a very clear displacement of the $250 \mathrm{hPa}$ flows, associated with the jet stream during the winter 2010, which showed an anomalous southern displacement compared to average winter conditions (Fig. 8A). Thus, dominant northwest $250 \mathrm{hPa}$ flows affecting the Iberian Peninsula are observed in the climatology (Fig. 8F), whereas, in 2010, there is a clearly dominant west and southwest flow direction. Thus, this pattern seems to be distinct for this extreme NAO winter, since most of the non-extreme, negative NAO winters (Fig. 8D, E) also show dominant northwest flows as is also true of the extreme episode in 1969 (Fig. 8B). Therefore, although the surface flows of the winter 2010 were comparable in direction and intensity to those observed in other extreme, negative NAO years, at the $250 \mathrm{hPa}$ level, 2010 seems to have demonstrated very anomalous behaviour.

\subsection{Synoptic scale features obtained with Lagrangean and Eulerian methods}

Displacement of the jet stream determined that storm tracks were anomalously shifted southward affecting the cyclonic activity off Iberia, northern Africa and most of the western and central sectors of the Mediterranean. This feature is illustrated in Fig. 9, which shows the frequency in the position of the centre 

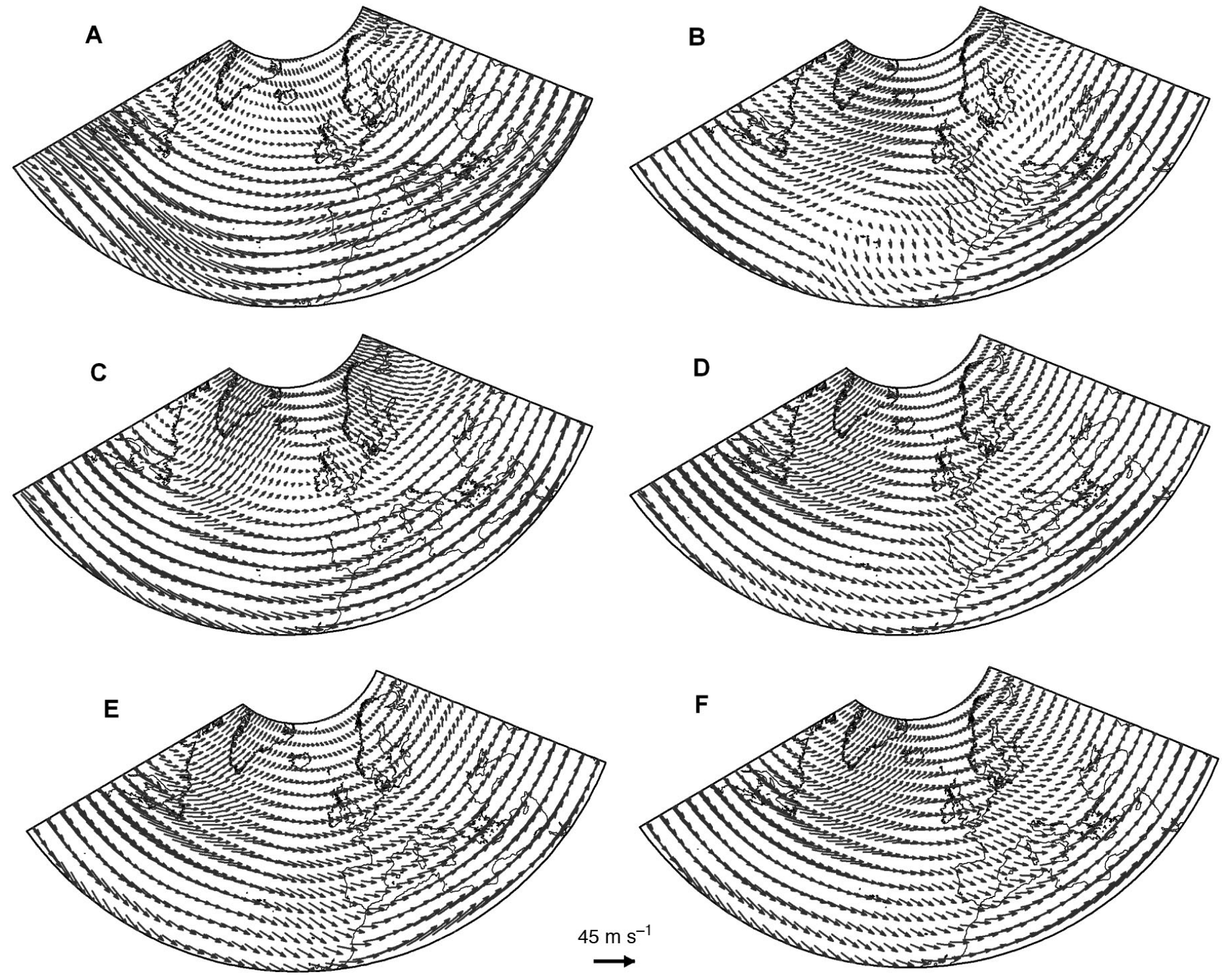

Fig. 8. Average direction and magnitude of $250 \mathrm{hPa}$ flows (A) in the winter 2010, (B) in the winter 1969, (C) in the winter 1996, (D) in the winters with NAO values between 0 and -1 (1948-2010), (E) in the winters with NAO values between -1 and -2 (1948-2010) and (F) climatology of the average direction and magnitude of $250 \mathrm{hPa}$ flows (1948-2010)

of storms with durations of over $2 \mathrm{~d}$ that affected the North Atlantic and Europe regions. In winter 2010 (Fig. 9A), there was a clear increase in the frequency of storm tracks over the North Atlantic Ocean at the latitude of the Iberian Peninsula compared to the climatology (Fig. 9F), in which the areas with a high frequency of winter storms $(>8)$ were found northward of the British Isles. This anomalous southward displacement in the high frequency of storm tracks has also been recorded for other extreme NAO years like 1969 (Fig. 9B) and 1996 (Fig. 9C), whereas, in the nonextreme, negative NAO winters (Fig. 9D,E), the frequency of storms at the latitudes near the Iberian Peninsula was much lower.
While the storm-tracking approach provides a Lagrangean perspective following the path of each individual cyclone, it can be appropriately complemented with an analysis based on a stationary Eulerian perspective, such as the weather typing approach. We analysed how the NAO affects the frequency of winter weather types on the Iberian Peninsula, and we found a significant correlation $(\mathrm{p}<0.05)$ with the frequency of SW (-0.46), W (-0.44) and, above all, C (-0.76) and A (0.82) weather types. The NAO, therefore, affects the frequency of the weather types most prone to cause precipitation in winter (SW, W and C) and the type that generally causes dry weather (A). Thus, a negative winter NAO is expected to cause a higher than aver- 

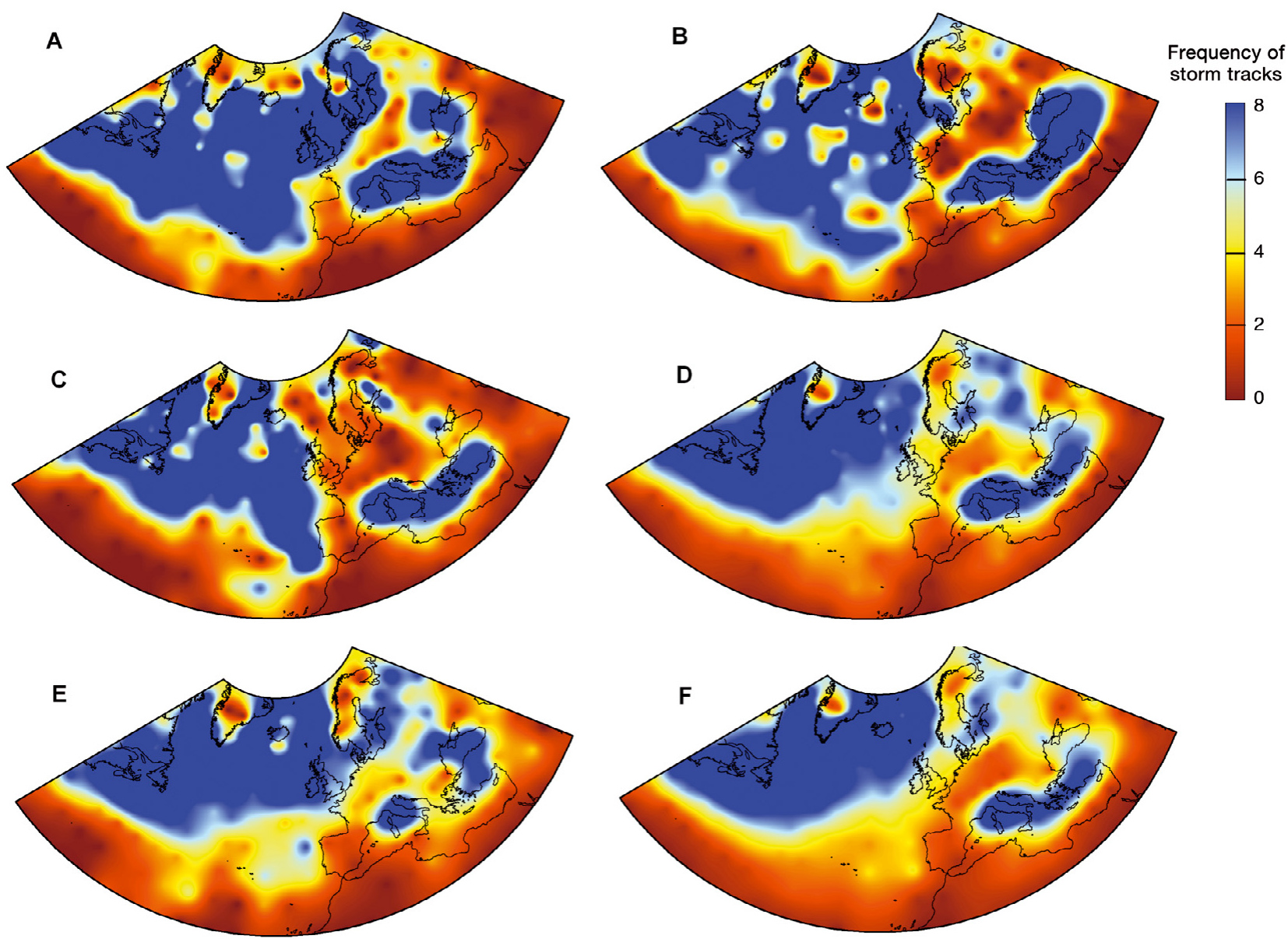

Fig. 9. Spatial distribution of the absolute frequency of winter storm tracks (A) in the winter 2010, (B) in the winter 1969, (C) in the winter 1996. Average frequency (D) in the winters with NAO values between 0 and $-1(1958-2010)$, (E) in the winters with NAO values between -1 and -2 (1958-2010) and (F) for all winters (1958-2010)

Table 2. Frequencies of different weather types. The table includes the winter long-term means (1900-2010); the values corresponding to the 10th and 90th percentiles of the series; the frequency of each weather type in the winters of 2010, 1969 and 1996; and the average frequency of weather types in the winters with North Atlantic Oscillation (NAO) values between 0 and -1 and between -1 and -2

\begin{tabular}{|c|c|c|c|c|c|c|c|c|}
\hline Weather type & $\begin{array}{c}\text { Mean frequency } \\
1900-2010\end{array}$ & $\begin{array}{c}\text { 90th } \\
\text { percentile }\end{array}$ & $\begin{array}{l}\text { 10th } \\
\text { percentile }\end{array}$ & $\begin{array}{l}\text { Winter } \\
2010\end{array}$ & $\begin{array}{l}\text { Winter } \\
1996\end{array}$ & $\begin{array}{l}\text { Winter } \\
1969\end{array}$ & $\begin{array}{l}\text { NAO } \\
0 \text { to }-1\end{array}$ & $\begin{array}{l}\text { NAO } \\
-1 \text { to }-2\end{array}$ \\
\hline North & 9 & 14 & 5 & 8 & 11 & 6 & 11 & 7 \\
\hline Northeast & 6 & 12 & 2 & 10 & 2 & 7 & 8 & 4 \\
\hline East & 6 & 11 & 2 & 6 & 8 & 2 & 7 & 5 \\
\hline Southeast & 6 & 10 & 2 & 3 & 9 & 8 & 4 & 4 \\
\hline South & 5 & 9 & 1 & 8 & 4 & 6 & 4 & 4 \\
\hline Southwest & 7 & 13 & 3 & 12 & 12 & 13 & 8 & 8 \\
\hline West & 7 & 12 & 2 & 12 & 9 & 12 & 8 & 13 \\
\hline Northwest & 9 & 13 & 4 & 5 & 12 & 8 & 8 & 11 \\
\hline Cyclonic & 18 & 28 & 9 & 28 & 36 & 25 & 20 & 27 \\
\hline Anticyclonic & 48 & 62 & 33 & 32 & 22 & 38 & 42 & 38 \\
\hline
\end{tabular}

age frequency of SW, W and C types and a low frequency of A types. The anomalous pressure pattern associated with a strong negative NAO and the wind circulation observed in the winter 2010 determined anomalous types of weather conditions affecting the Iberian Peninsula. During the winter 2010, 32 d were classified as anticyclonic, whereas the long-term average frequency in winter was $48 \mathrm{~d}$ (Table 2). In contrast, $28 \mathrm{~d}$ were classified as cyclonic, whereas the long-term winter average was $18 \mathrm{~d}$. Simultaneously, the main weather types driving precipitation in the western and south-western Iberian Peninsula (i.e. south-western 
and western directional weather types) were recorded on $24 \mathrm{~d}$ in winter 2010, whereas the long-term daily average was $14 \mathrm{~d}$. In the winter 2010, the weather types most prone to cause precipitation $(\mathrm{C}, \mathrm{SW}$ and $\mathrm{W})$ showed a frequency of close to or more than the 90th percentile of the series. Nevertheless, the anomaly in the frequency of these weather types does not seem to explain the large precipitation anomalies recorded in the winter 2010, since the same, or an even higher, frequency of these weather types has been recorded during other negative NAO winters, such as 1969 or 1996, in which precipitation anomalies were much more moderate than those recorded in 2010 . Thus, the average frequencies of $\mathrm{C}, \mathrm{SW}$ and $\mathrm{W}$ weather types are similar to the averages for the winters with NAO values between -1 and -2 . Therefore, the anomalous frequency of weather types during the winter 2010, although prone to cause high precipitation, would not, by itself, explain the anomalous precipitation during the winter 2010.

\section{FUTURE SCENARIOS OF WINTER NAO INDEX}

The previous analysis confirms that the extreme precipitation observed in the winter 2010 was associated with anomalous and persistent strong negative conditions of the NAO pattern, which determined the magnitude and direction of the wind flows that affected the Iberian Peninsula. At daily and sub-weekly scales we showed that the NAO mode steered the trajectories of many storms associated with the Polar front on a southward track and induced an abnormally high frequency of the weather types that determine precipitation in Iberia. It is expected that future extreme NAO conditions, similar to those observed in 2010 (and other years with extreme NAO winters) may also cause extreme precipitation on the Iberian Peninsula.
To project the future occurrence of extreme phases of the NAO it is necessary to check the accuracy of current state-of-the-art GCMs in reproducing the NAO values observed during the period of available measured data. Table 3 shows the absolute frequencies of the negative NAO values during the period 1875-2010 under the consideration of different thresholds, representing $20 \%(-0.84), 10 \%(-1.28), 5 \%(-1.65)$ and $1 \%$ $(-2.33)$ of the probability distribution function of the NAO index values. The observed frequencies of Jones et al.'s (1997) NAO index, the frequencies obtained by 10 different GCMs and the empirical frequencies according to the length of the dataset are also shown. The table shows how the occurrence of the extreme, negative NAO values $(<-2.33)$ is 2 for observations, with most models providing similar values in a range of between 0 and 5 extreme events. The number of observed winters with a NAO below -1.65 in the period between 1875 and 2010 was 6, similar to the expected empirical probability (7), and most of the models reproduce this value, with a range of between 6 and 9 events. The same pattern was observed for NAO values that fall within the thresholds of -1.28 and -0.84 . Thus, we can conclude that the $10 \mathrm{GCMs}$ used are very accurate in reproducing the observed frequencies of the most extreme, negative NAO events. Thus, we have also used these models to determine the expected frequency of NAO events between 2011 and 2099. Table 3 shows that, according to empirical frequencies, 1 event below -2.33 , 4 events below -1.65 , 9 events below -1.28 and 18 events below -0.84 are expected. Most of the models show a lower frequency of the most extreme NAO values compared to expected frequencies. Thus, 5 of the models do not predict any occurrence of a NAO winter with a value below -2.33 , and 7 of the models predict a lower frequency of events below -1.65 compared to empirical frequencies. The decrease in the frequency of negative NAO values

Table 3. Observed and predicted frequencies of winter negative NAO (1875-2010) values considering 4 upper thresholds and the predicted frequencies for the same 4 upper thresholds for the 2011-2099 period. Data for 10 available models are also shown. The expected frequencies (empirical) are given according to the length of the 1875-2010 and 2011-2099 periods. BCM: BCCR/BCM2.0; CNRM: CNRM/CM3; CSIRO: CSIRO Mk3.5; GFDL: GFDL/CM2.0; MIROC: MIROC 3.2; MIUB: ECHO-G/MIUB; MPI: ECHAM5/MPI OM; MRI: MRI-CGCM2.3.2; UKMO: UKMO-HADCM3; CCMA: CCMA-CGCM3.1_T63

\begin{tabular}{|c|c|c|c|c|c|c|c|c|c|c|c|c|}
\hline Threshold & Empirical & Observed & BCM & CNRM & CSIRO & GFDL & MIROC & MIUB & MPI & MRI & UKMO & CCMA \\
\hline \multicolumn{13}{|l|}{$1875-2010$} \\
\hline-2.33 & 1 & 2 & 1 & 0 & 1 & 0 & 2 & 5 & 3 & 2 & 1 & 0 \\
\hline-1.65 & 7 & 6 & 6 & 8 & 6 & 8 & 8 & 8 & 7 & 6 & 9 & 6 \\
\hline-1.28 & 14 & 15 & 12 & 17 & 16 & 15 & 15 & 12 & 13 & 12 & 17 & 15 \\
\hline-0.84 & 27 & 27 & 31 & 31 & 28 & 29 & 27 & 27 & 28 & 28 & 27 & 32 \\
\hline \multicolumn{13}{|l|}{ 2011-2099 } \\
\hline-2.33 & 1 & & 0 & 0 & 1 & 0 & 0 & 0 & 1 & 2 & 1 & 1 \\
\hline-1.65 & 4 & & 2 & 2 & 2 & 0 & 1 & 2 & 4 & 7 & 3 & 4 \\
\hline-1.28 & 9 & & 4 & 5 & 4 & 0 & 5 & 4 & 5 & 13 & 5 & 10 \\
\hline-0.84 & 18 & & 9 & 11 & 14 & 10 & 9 & 9 & 13 & 24 & 13 & 20 \\
\hline
\end{tabular}




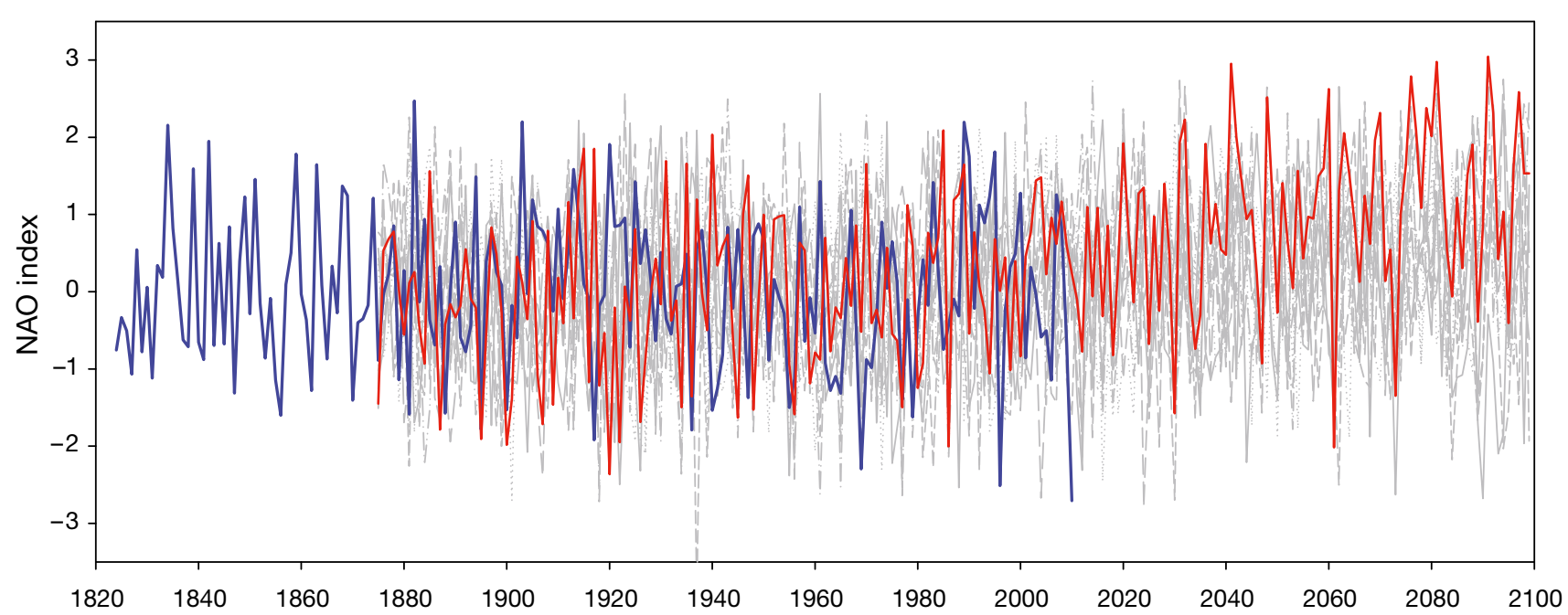

Fig. 10. Observed (1823-2010) and modelled winter (DJFM) NAO index (1875-2100) from the 10 global climate models used in the present study. Grey: 10 individual models; blue: observed NAO; red: a multimodel approach

seems to reflect a general tendency for the future. Fig. 10 shows the evolution of the observed NAO values between 1824 and 2010 and the predictions of the 10 GCMs used from 1875 to 2100. The figure also includes multimodel NAO predictions obtained with the average of the pressure fields from the 10 different models. Between 1875 and 2010 the range of variability between the observations and the model predictions was similar, with no trends recorded during the period. This pattern was also observed for the model predictions until 2039. However, from 2040 onwards, most model outputs and the multimodel average show a clear increase in NAO index values, with a positive and gradual evolution up to the end of the 20th century. This would explain the lower frequencies of the most extreme, negative winter NAO values listed in Table 3, but we must also take into account that half of the GCMs still predicted the occurrence of extreme, negative NAO winters (below the -2.33 and -1.65 thresholds), with frequencies similar to those expected empirically. Therefore, although with decreasing likelihood, it seems reasonable to expect extreme, negative winters in the future, with NAO values of similar magnitude to those observed in 2010. Thus, winters with very extreme precipitation induced by intense negative NAO are likely to decrease during the 21st century, but they remain possible.

\section{DISCUSSION AND CONCLUSIONS}

The present study has illustrated the substantial effects of the extreme, negative winter NAO on the precipitation in western and southern Iberia. The winter NAO pattern, characterised by an intense north- south SLP dipole over the North Atlantic region, was clearly identified in the winter 2010. These pressure anomalies set a new record for the most extreme, negative NAO index values quantified since 1823 (Jones et al. 1997). In 2010 the extreme, negative NAO conditions caused the dominant, humid Atlantic flows from south-westerly and westerly directions that affected most of the Iberian Peninsula. The SLP pattern has been associated with a southern displacement of the jet stream and also the high number of polar storms that affected the Iberian Peninsula and Mediterranean basin, for the most part above the average winter frequency (as shown in Trigo 2006). These patterns determined that the weather types prone to cause precipitation on the Iberian Peninsula (cyclonic and advectives of west and southwest) had a very high frequency in the winter 2010 .

At the regional scale, the main consequence of the anomalous atmospheric conditions was the extremely high levels of precipitation on most of the Iberian Peninsula during the winter 2010, with a clear northsouth gradient that resembles the widely recognised influence of the NAO in the region (Rodríguez-Puebla et al. 1998, Trigo et al. 2002). Thus, the northern and eastern coastlands, where the effect of the winter NAO on precipitation is usually weaker, did not display positive precipitation anomalies during the winter 2010. In contrast, the strongest positive anomalies were recorded in western and southern areas, where precipitation is primarily controlled by the NAO. Moreover, in these areas, the most extreme precipitation events at a daily time scale were recorded during the days with the strongest negative NAO index. In addition, the extreme seasonal precipitation was related to both the large increase in the frequency of rainy days and the 
frequency of daily extreme precipitation events, although some spatial differences were found to play a role in both phenomena. For example, in Atlantic coastlands, the frequency of rainy days did not show a large anomaly; rather, the large values of the precipitation observed were a consequence of the high frequency of extreme daily precipitation events.

We must note that most of the anomalous atmospheric conditions recorded during the winter 2010 are comparable to other extreme, negative NAO winters such as 1996, in which more moderate precipitation was recorded. For example, the anomalous frequency of weather types prone to cause precipitation was similar to the frequency recorded in other negative NAO winters. Also, the intensity and direction of the wind surface flows were similar to those observed for other negative winters (i.e. 1969 and 1996). Nevertheless, in the winter 2010 some particularities were recorded that would explain the extremely high precipitation recorded in large areas of the Iberian Peninsula. For example, the SLP gradient between the north and south of the North Atlantic region, characteristic of the NAO dipole (Hurrell et al. 2003), was very intense in the winter 2010, only comparable with the winter of 1969, and very different-in terms of the magnitude of the anomalies - with that observed in other negative NAO winters. Even the second strongest winter NAO (1996) showed lower SLP anomalies, mainly in the southern part of the NAO dipole, which affects the Iberian Peninsula. The main difference in the atmospheric mechanisms recorded in 2010 versus in other negative NAO winters was recorded in the $250 \mathrm{hPa}$ flows, which, in 2010, showed a clear displacement to the south, with a dominant southwest pattern and a high intensity that affected the Iberian Peninsula. Thus, the winter of 2010 evidenced a very anomalous displacement of the mid-latitude jet stream (L'Hereux et al. 2010), which had not previously been observed in any other winter NAO. Thus, this displacement directly affected the western and southern areas of the Iberian Peninsula, with an above-average frequency of cyclones crossing the region. Therefore, the main atmospheric mechanisms, which may explain the exceptional precipitation recorded on the Iberian Peninsula during winter 2010, were associated with a very negative NAO, but were more strongly linked to the anomalous conditions in the mid-troposphere than to the surface anomalies.

An interesting characteristic of the winter 2010 was the persistence of rainy days, with an anomalously high frequency over most of the Iberian Peninsula. Thus, the NAO, measured at a daily scale, showed a high persistence of negative values, with 2 periods of 35 and 65 consecutive days in which the daily NAO index was continuously negative. The winter 2010 showed a high persistence of blocking conditions in the North Atlantic region (Cattiaux et al. 2010), which commonly caused a displacement of the mid- to hightroposphere flows to more southern latitudes (Barriopedro et al. 2006). Such a pattern was ultimately responsible for the large anomaly found in the average direction and intensity of the $250 \mathrm{hPa}$ flows and the southern displacement of the mid-latitude jet stream (Cattiaux et al. 2010).

Climate change scenarios obtained with different GCMs reveal that a significant decrease of precipitation in this region can be expected (Solomon et al. 2007). In addition, future projections of the NAO index based on GCMs show a general, positive trend throughout the 21st century (e.g. Osborn et al. 1999, Demuzere et al. 2009). Despite the positive trend, GCMs inform that extreme, negative NAO conditions, as strong as that observed for the winter 2010, will still be recorded in the future, which, according to results of this work, may cause very high precipitation in the southern and western parts of the Iberian Peninsula. Nevertheless, we must bear in mind that present climate models are still unable to consistently replicate the observed amplitude of the interannual variability and of important modes, e.g. the NAO (Osborn 2004, Solomon et al. 2007), and therefore some uncertainties may remain in the presented projections.

Acknowledgements. This work was supported by the research projects CGL2008-01189/BTE and CGL2006-11619/ HID, financed by the Spanish Commission of Science and Technology and FEDER; by EUROGEOSS (FP7-ENV-2008-1226487) and ACQWA (FP7-ENV-2007-1-212250), financed by the VII Framework Programme of the European Commission; and 'La nieve en el Pirineo aragonés: distribución espacial y su respuesta a las condiciones climáticas', financed by 'Obra Social La Caixa' and the Aragón Government. Ricardo Trigo's work was partially supported by the FCT (Portugal) through project ENAC (PTDC/AAC-CLI/103567/2008).

\section{LITERATURE CITED}

Austin RB, Cantero-Martínez C, Arrúe JL, Playán E, CanoMarcellán P (1998) Yield-rainfall relationships in cereal cropping systems in the Ebro river valley of Spain. Eur J Agron 8:239-248

Baldwin MP, Dunkerton TJ (1999) Propagation of the Arctic Oscillation from the stratosphere to the troposphere. J Geophys Res 104:30937-30946

Barriopedro D, García-Herrera R, Lupo A, Hernández E (2006) A Climatology of Northern Hemisphere Blocking. J Clim 19:1042-1063

Brönnimann S (2007) Impact of El Niño-Southern Oscillation on European climate. Rev Geophys 45. doi:10.1029/2006 RG000199

> Brönnimann S, Luterbacher J, Staehelin J, Svendby TM, Hansen G, Svenøe T (2004) Extreme climate of the global troposphere and stratosphere in 1940-42 related to El Niño. Nature 431:971-974 
Cattiaux J, Vautard R, Cassou C, Yiou P, Masson-Delmotte V, Codron F (2010) in Europe: a cold extreme in a warming climate. Geophys Res Lett 37. doi:10.1029/2010GL044613

Demuzere M, Werner M, van Lipzig NPM, Roeckner E (2009) An analysis of present and future ECHAM5 pressure fields using a classification of circulation patterns. Int $\mathrm{J}$ Climatol 29:1796-1810

Hurrell JW (1995) Decadal trends in North Atlantic Oscillation: regional temperatures and precipitation. Science 269:676-679

Hurrell JW, Van Loon H (1997) Decadal variations in climate associated with the North Atlantic Oscillation. Clim Change 36:301-326

Hurrell JW, Kushnir Y, Ottersen G, Visbeck M (2003) An overview of the North Atlantic Oscillation. The North Atlantic Oscillation: climate significance and environmental impact. Geophys Monogr 134:1-36

Jenkinson AF, Collison P (1977) An initial climatology of Wales over the North Sea. Synoptic Climatology Branch Memorandum 62, Meteorological Office, London

> Jones PD, Jónsson T, Wheeler D (1997) Extension to the North Atlantic Oscillation using early instrumental pressure observations from Gibraltar and south-west Iceland. Int J Climatol 17:1433-1450

Kalnay E, Kanamitsu M, Kistler R, Collins W and others (1996) The NCEP/NCAR 40-year reanalysis project. Bull Am Meteorol Soc 77:437-471

L'Heureux M, Butler A, Jha B, Kumar A, Wang W (2010) Unusual extremes in the negative phase of the Arctic Oscillation during 2009. Geophys Res Lett 37. doi:10.1029/ 2010GL043338

> López-Moreno JI, Vicente-Serrano SM (2007) Atmospheric circulation influence on the interannual variability of snowpack in the Spanish Pyrenees during the second half of the twentieth century. Nord Hydrol 38:33-44

López-Moreno JI, Vicente-Serrano SM, Beguería S, GarcíaRuiz JM, Portela MM, Almeida AB (2009) Downstream propagation of hydrological droughts in highly regulated transboundary rivers: the case of the Tagus River between Spain and Portugal. Water Resour Res 45:W02405. doi: 10.1029/2008WR007198

Lorenzo-Lacruz J, Vicente-Serrano SM, López-Moreno JI, Beguería S, García-Ruiz JM, Cuadrat JM (2010) The impact of droughts and water management on various hydrological systems in the headwaters of the Tagus River (central Spain). J Hydrol (Amst) 386:13-26

McKee TBN, Doesken J, Kleist J (1993) The relationship of drought frequency and duration to time scales. In: Proc 8th Conf on Applied Climatology. Am Meteorol Soc p 179-184

Osborn TJ (2004) Simulating the winter North Atlantic Oscillation: the roles of internal variability and greenhouse gas forcing. Clim Dyn 22:605-623

Osborn TJ, Briffa KR, Tett SFB, Jones PD, Trigo RM (1999) Evaluation of the North Atlantic Oscillation as simulated by a coupled climate model. Clim Dyn 15:685-702

Editorial responsibility: Luis Gimeno,

Ourense, Spain
Rodríguez-Puebla C, Encinas AH, Nieto S, Garmendia J (1998) Spatial and temporal patterns of annual precipitation variability over the Iberian Peninsula. Int J Climatol 18:299-316

Seager R, Kushnir Y, Nakamura J, Ting M, Naik N (2010) Northern Hemisphere winter snow anomalies: ENSO, NAO and the winter of 2009/10. Geophys Res Lett 37. doi:10.1029/2010GL043830

Solomon S, Qin D, Manning M, Alley RB and others (2007) Technical summary. In: Solomon S, Qin D, Manning M, Chen Z, Marquis M, Averyt KB, Tignor M, Miller HL (eds) Climate Change 2007: the physical science basis. Contribution of Working Group I to the 4 th assessment report of the Intergovernmental Panel on Climate Change. Cambridge University Press, Cambridge

> Trenberth KE, Guillemot ChJ (1996) Physical processes involved in the 1988 drought and 1993 floods in north America. J Clim 9:1288-1298

Trenberth KE, Paolino DA Jr (1980) The Northern Hemisphere sea-level pressure data set: trends, errors, and discontinuities. Mon Weather Rev 108:855-872

Trigo IF (2006) Climatology and interannual variability of storm-tracks in the Euro-Atlantic sector: a comparison between ERA-40 and NCEP/NCAR reanalyses. Clim Dyn 26:127-143

Trigo RM, DaCamara C (2000) Circulation weather types and their influence on the precipitation regime in Portugal. Int J Climatol 20:1559-1581

Trigo IF, Trevor DD, Grant RB (1999) Objective climatology of cyclones in the Mediterranean region. J Clim 12:1685-1696

> Trigo RM, Osborn TJ, Corte-Real JM (2002) The North Atlantic Oscillation influence on Europe: climate impacts and associated physical mechanisms. Clim Res 20:9-17

> Vicente-Serrano SM (2005) El Niño and La Niña influence on drought conditions at different time scales in the Iberian Peninsula. Water Resour Res 41:W12415. doi:10.1029/2004 WR003908

Vicente-Serrano SM (2006) Differences in spatial patterns of drought on different time scales: an analysis of the Iberian Peninsula. Water Resour Manag 20:37-60

- Vicente-Serrano SM, Cuadrat JM, Romo A (2006) Early prediction of crop productions using drought indices at different time scales and remote sensing data: application in the Ebro valley (north-east Spain). Int J Remote Sens 27:511-518

- Wallace JM (2000) North Atlantic Oscillation/annular model: two paradigms-one phenomenon. QJR Meteorol Soc 126: 791-805

Wang C, Liu H, Lee S (2010) The record-breaking cold temperatures during the winter of 2009/2010 in the Northern Hemisphere. Atmos Sci Lett. doi:10.1002/asl.278

> Zezere JL, Trigo RM, Fragoso M, Oliveira SC, Garcia RAC (2008) Rainfall-triggered landslides in the Lisbon region over 2006 and relationships with the North Atlantic Oscillation. Nat Hazards Earth Syst Sci 8:483-499

Submitted: July 14, 2010; Accepted: November 18, 2010

Proofs received from author(s): January 19, 2011 